\title{
BEAR LAKE FORMATION MICROPROBE DATA
}

\author{
by
}

Cheryl Hartbauer ${ }^{1}$

Microprobe data were collected as part of a study to test the hypotheses that the composition of the Bear Lake Formation (fig. 1) reflects progressive erosion of Tertiary and Mesozoic units of the Alaska Peninsula, and that diagenetic minerals present in the Bear Lake Formation reflect conditions implied by thermal maturity indicators. Five samples were analyzed in order to characterize the composition of volcanic rock fragments, other framework clasts, and diagenetic minerals. These samples are all sandstones from outcrops of the Bear Lake Formation in the Port Moller area of the Alaska Peninsula (fig. 2). Major oxide compositions were measured using the Cameca SX-50 electron microprobe at the Advanced Instrumentation Laboratory at the University of Alaska Fairbanks.

Three samples were taken from measured stratigraphic sections and were analyzed using a 2-micron beam with $15 \mathrm{KeV}$ and $10 \mathrm{nA}$. Pore-lining clay of a sodic illite composition and pore-filling zeolites were identified in sample BL2-176 (fig. 3). Chemical composition and cursory XRD analysis suggest that these zeolites are heulandite. Other minerals identified in these samples include plagioclase (An1-68), potassium feldspar, hornblende, glauconite, and smectite. Albite (An1-5) occurs as a pore-filling mineral and replaces plagioclase of higher anorthite content. Samples BL5-92 and BL2176 contain both zeolite and albite.

Analysis of two additional samples focused on classifying volcanic rock fragments. A 20-micron beam was used with $15 \mathrm{KeV}$ and $10 \mathrm{nA}$. Individual phenocrysts in each clast were analyzed and averaged with measurements of the groundmass to approximate a whole-rock composition. For fragments with phenocrysts smaller than 20 microns, individual points that included a combination of phenocryst and groundmass were measured and averaged to approximate a whole-rock composition.

Forty-six volcanic rock fragments were analyzed from sample 04RR163b. Both felsic and intermediate volcanic fragments were identified, with a notable absence of mafic fragments (fig. 4). Classification based on comparison with average major-oxide compositions of volcanic rock types agrees extremely well with classification based on the total alkali-silica diagram. Phenocrysts identified include pyroxene, hornblende, and plagioclase (fig. 5). Both clinopyroxene and orthopyroxene were identified, with clinopyroxene being the more prevalent of the two. Anorthite content of the plagioclase ranges from An44 to An69. In addition, some quartz phenocrysts were identified in the felsic volcanic fragments.

Twenty-six volcanic rock fragments were analyzed from sample 04RR152b. The majority of these fragments have been altered to the point that their compositions no longer resemble those of volcanic rocks. Groundmass has been replaced by clay, and in some fragments plagioclase is albitized or replaced by calcite (fig. 6). Compositionally, a number of fragments still appear volcanic, but the total alkali-silica diagram could not be used to classify these fragments due to mobility of $\mathrm{Na}$ and $\mathrm{K}$. Instead, the data were compared to average volcanic rock compositions with emphasis on the relatively non-mobile elements Si and Ti. These fragments were found to be of intermediate and felsic composition, ranging from basaltic andesite to rhyolite (fig. 7).

In general, microprobe analysis of these five samples from the Bear Lake Formation shows that volcanic fragments are slightly to severely altered, and of felsic and intermediate composition. This characterization will aid in provenance identification. Recognition of compositional variations and refinement of provenance interpretation for the Bear Lake Formation will provide a foundation for interpreting the tectonic dynamics of the Alaska Peninsula during the Miocene. The identification of pore-filling and replacement minerals, such as zeolite and albite, helps to characterize the diagenetic mineralogy of the Bear Lake Formation. Considering this mineralogy in conjunction with existing thermal maturation data will aid in understanding the diagenetic conditions that this formation has experienced in the Port Moller area.

\section{REFERENCES}

Reifenstuhl, R.R., Shafer, D.C., Ryherd, T.J., Brizzolara, D.W., and Blodgett, R.B., 2004, Summary of May 25-June 4, 2004, field notes and samples, Puale Bay and Wide Bay areas, Alaska Peninsula: Alaska Division of Geological \& Geophysical Surveys Raw Data File 2004-3, 16 p.

Streckeisen, A., 1976, To each plutonic rock its proper name: Earth Science Review, v. 12, p. 1-33.

${ }^{1}$ Univeristy of Alaska, Department of Geology \& Geophysics, P.O. Box 757320, Fairbanks, Alaska 99775-7320; fsclr2@uaf.edu 


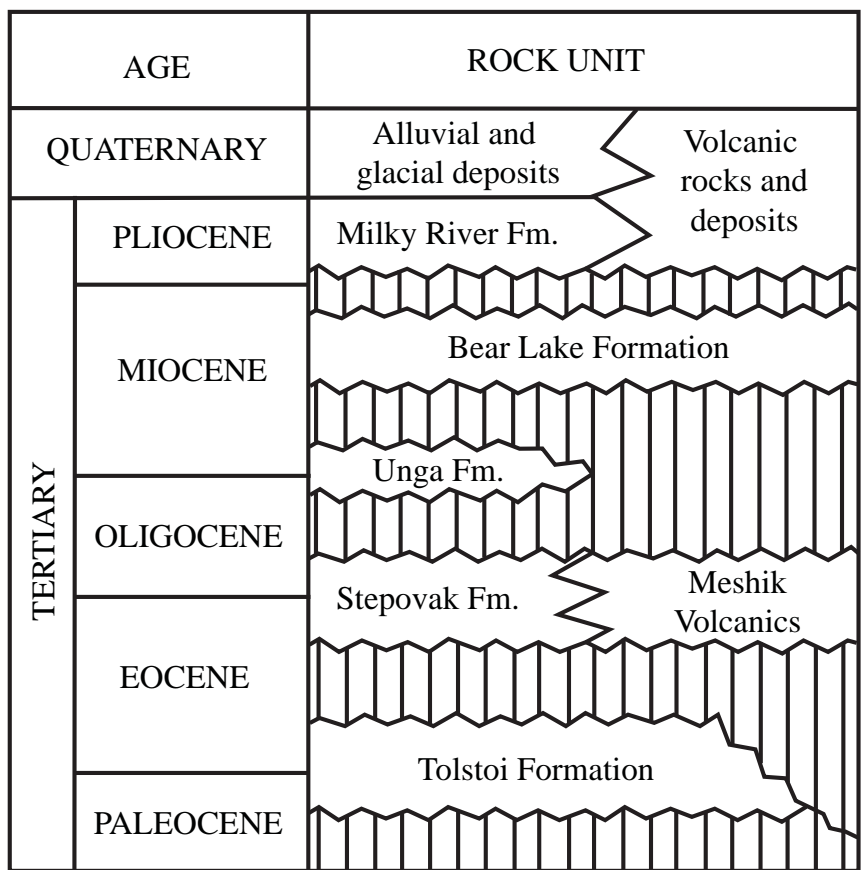

Figure 1. Tertiary stratigraphic column for the Alaska Peninsula (modified from Reifenstuhl and others, 2004).

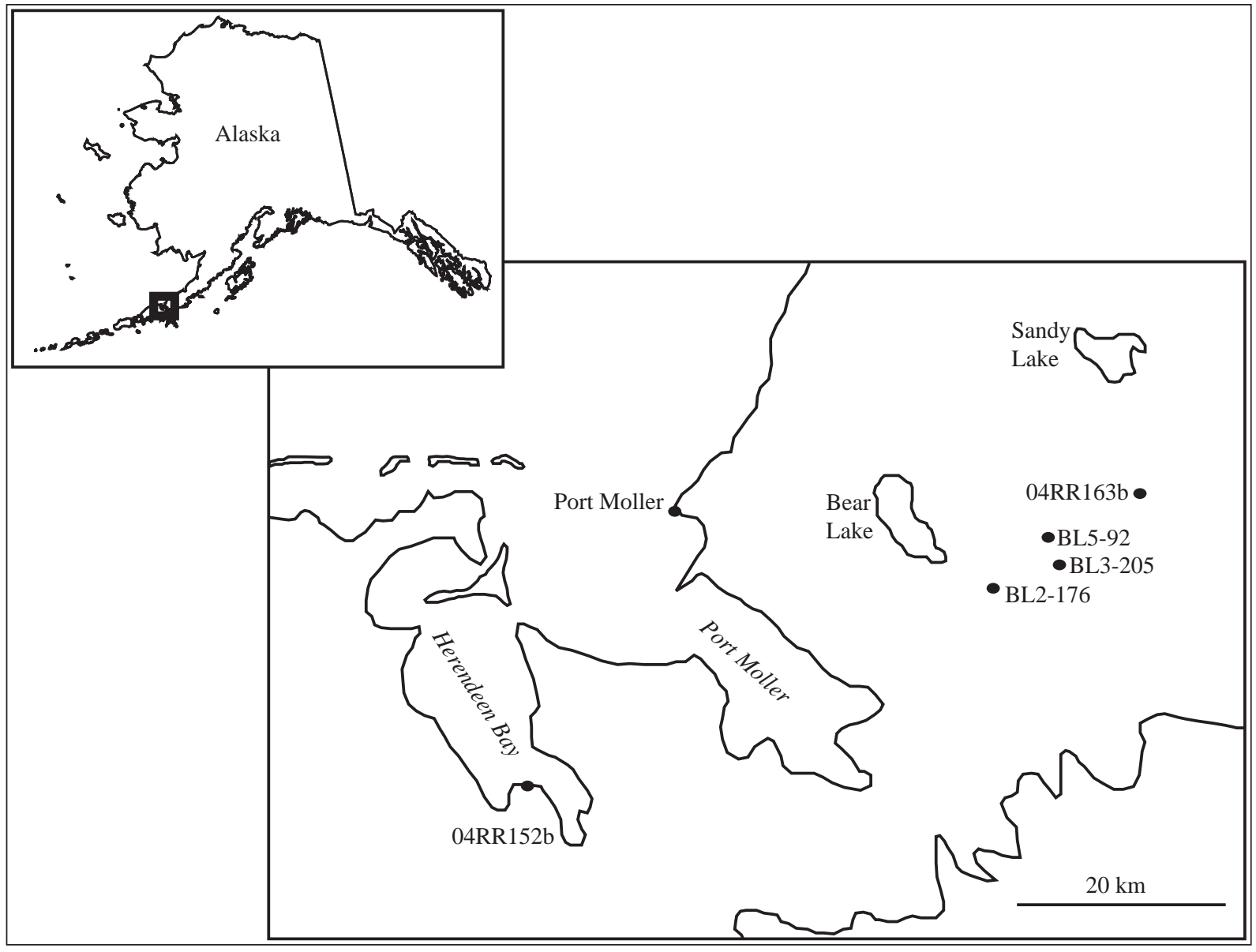

Figure 2. Location of Bear Lake Formation outcrop samples used in microprobe analysis. BL prefix indicates samples from measured stratigraphic sections. 
Figure 3. Photomicrograph of pore-lining illite (arrow) and pore-filling zeolite $(\mathrm{Z})$ in sample BL2-176.

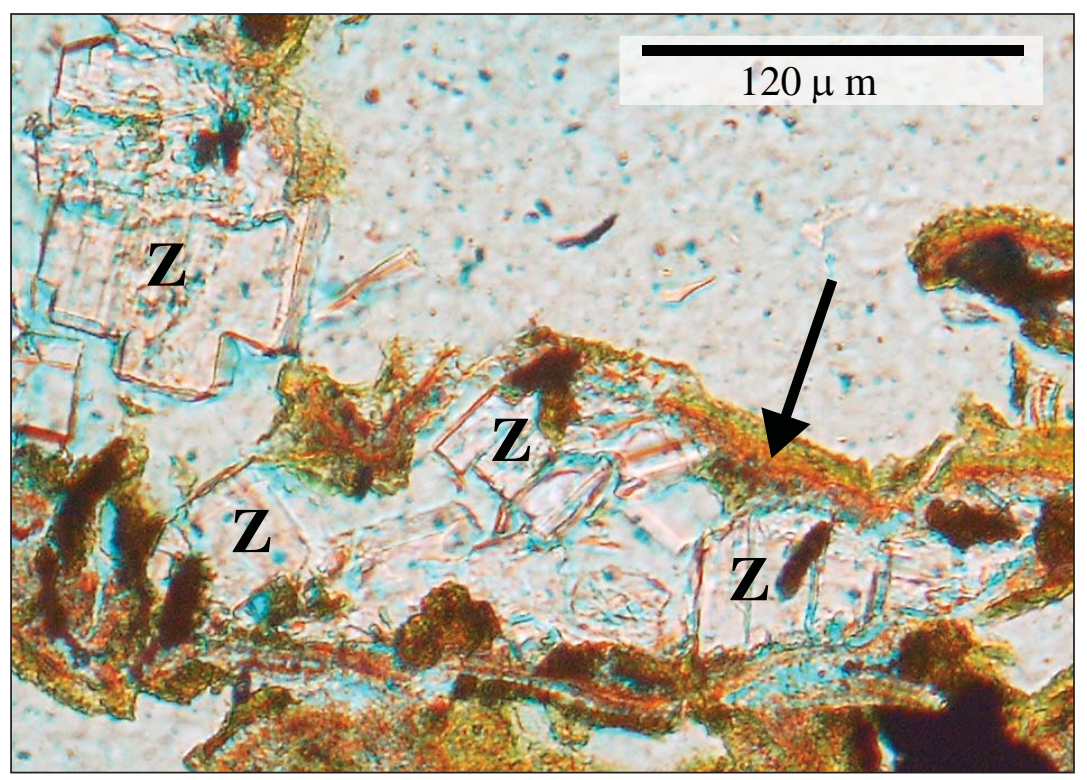

\section{Classification of Volcanic Rock Fragments Sample 04RR163b}

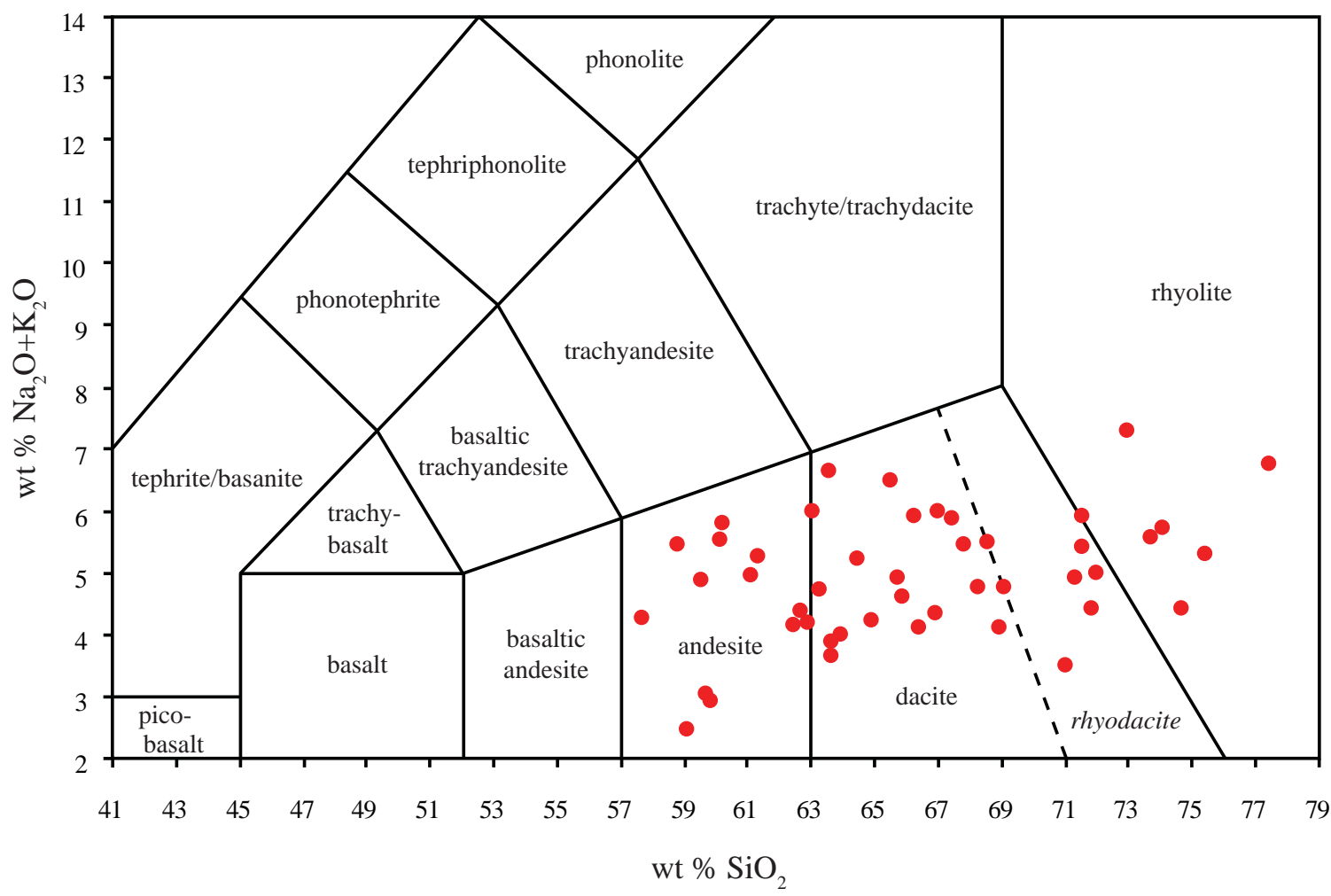

Figure 4. Total alkali-silica plot for volcanic rock fragments analyzed in sample 04RR163b. 


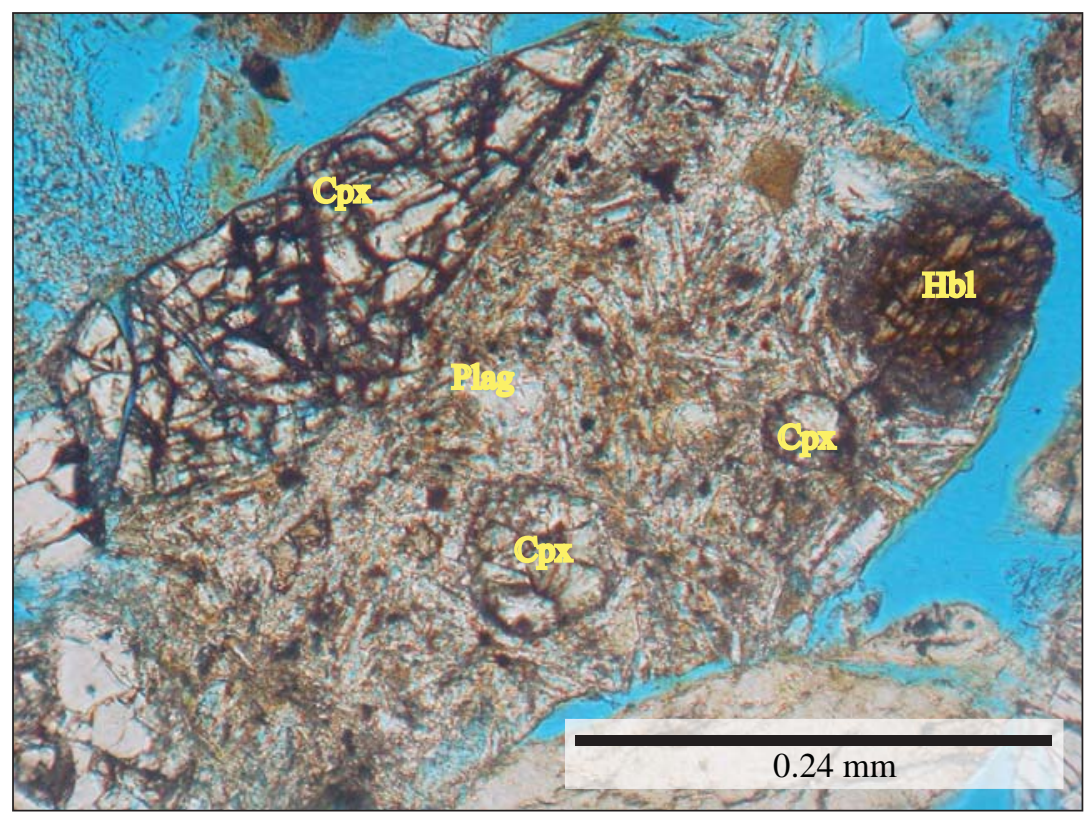

Figure 5. Photomicrograph of volcanic rock fragment in sample 04RR163b with hornblende ( $\mathrm{Hbl})$, clinopyroxene (Cpx), and plagioclase (Plag) (An56) phenocrysts.

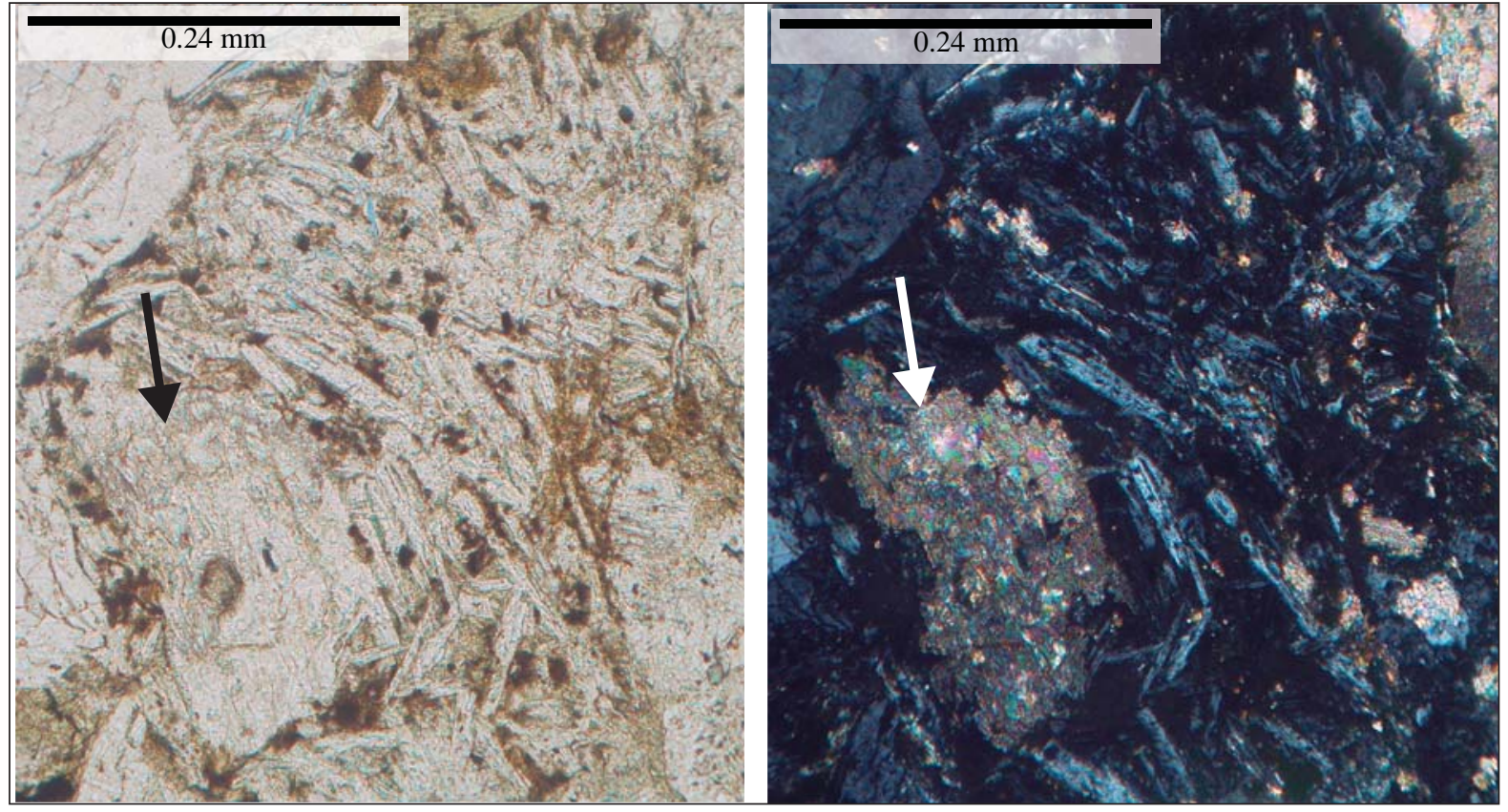

Figure 6. Photomicrograph of volcanic rock fragment in sample 04RR152b with calcite-altered plagioclase (arrow). Shown in plane-polarized light (left) and with crossed polars (right). 


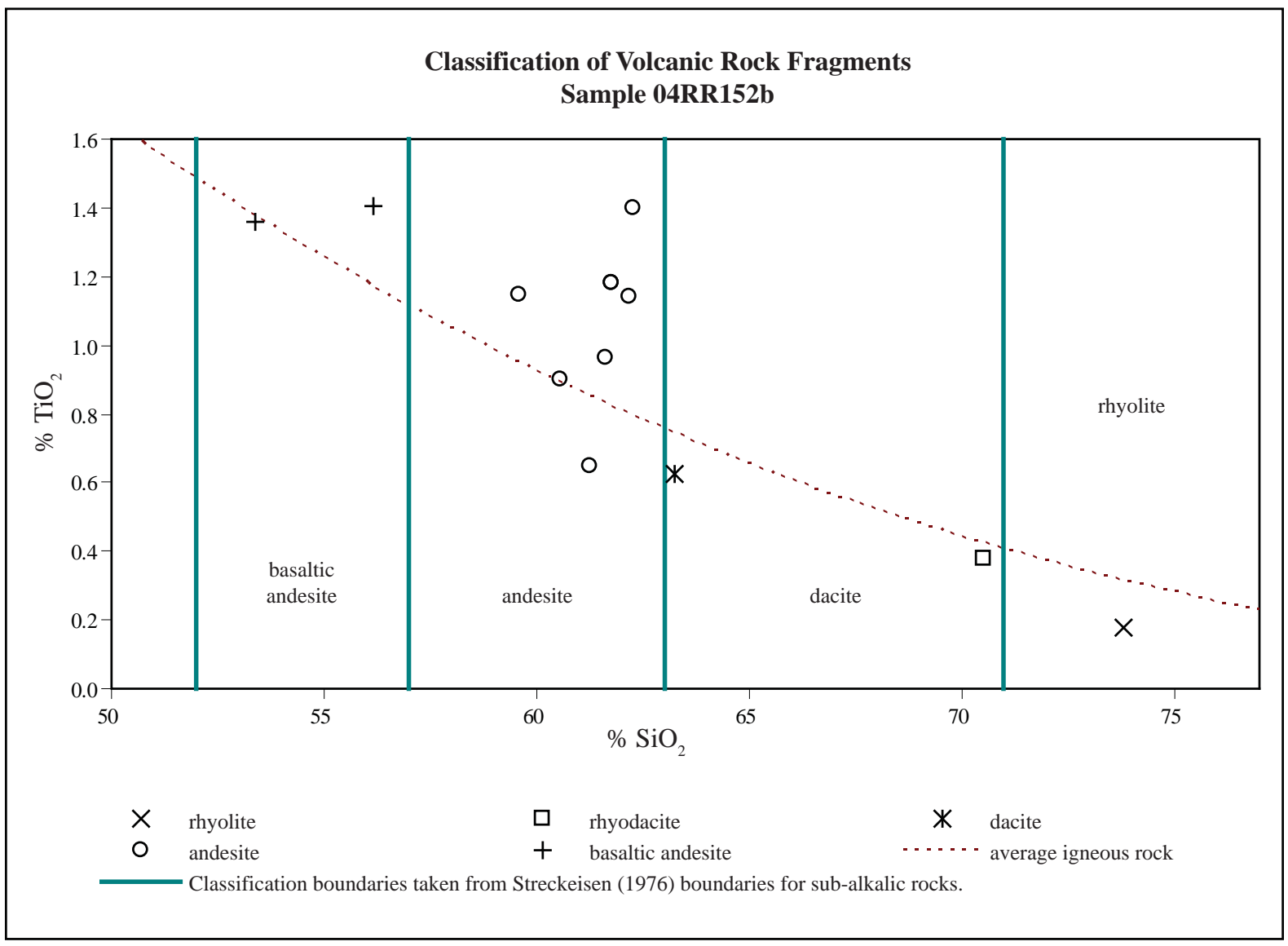

Figure 7. $\mathrm{SiO}_{2}$ vs $\mathrm{TiO}_{2}$ plot for selected altered volcanic rock fragments analyzed in sample 04RR152b. Classification boundaries are taken from Streckeisen (1976) boundaries for sub-alkalic rocks. The dashed curve is an average trend for 18,170 relatively unaltered igneous rocks. 